\title{
Degenerative spondylolisthesis: surgical treatment
}

\section{ESPONDILOLISTESE DEGENERATIVA: TRATAMENTO CIRÚRGICO}

Authorship: Brazilian Society of Neurosurgery; Brazilian Society of Orthopedics and Traumatology Participants: Ricardo V. Botelho; Noel O. Foni; Alberto O. Gotfryd; Carlos Fernando P.S. Herrero; Jefferson Daniel; Robert Meves; Marcelo Luis Mudo; Ricardo S. Simões; Sérgio Zylbersztejn; Wanderley M. Bernardo Conflict of interest: no conflict of interest informed.

The Guidelines Project, an initiative of the Brazilian Medical Association, aims to combine information from the medical field in order to standardize procedures to assist the reasoning and decision-making of doctors.

The information provided through this project must be assessed and criticized by the physician responsible for the conduct that will be adopted, depending on the conditions and the clinical status of each patient.

\section{DESCRIPTION OF THE EVIDENCE COLLECTION METHOD}

To develop this guideline the following primary and secondary electronic databases were consulted: Medline (1966-2009), Cochrane, Cochrane Central Register of Controlled Trials - Central, Embase (1980-2010) and Lilacs (1982-2010). The search for evidence came from actual clinical scenarios and used keywords (MeSH terms) grouped in the following syntax: surgical procedures, operative, nonsurgical,therapy, lumbosacral region, lumbosacral, degenerative, spondylolisthesis, spondylolisthesis. The articles were selected after critical evaluation of the strength of scientific evidence by specialists from the participating Medical Associations, and publications of greatest strength were used for recommendation. The recommendations were drawn from group discussion. The entire guideline was reviewed by an independent group specializing in evidence-based clinical guidelines.

\section{Grade Of RECOMmEndation AND STRENGTH OF EVIDENCE}

A. Experimental or observational studies of higher consistency.

B. Experimental or observational studies of lower consistency.

C. Case reports (non-controlled studies).

D. Opinions without critical evaluation, based on consensus, physiological studies, or animal models.

\section{Овjective}

This guideline's target audience comprises general practitioners, rheumatologists, orthopedists, physiatrists, neurologists and neurosurgeons in order to be able to guide patients with lower back pain and/or sciatic pain resis- tant to non-operative treatment caused by lumbar degenerative spondylolisthesis regarding the indication for surgical treatment.

\section{INTRODUCTION}

Degenerative spondylolisthesis refers to a forward slippage of a lumbar, with an intact neural arch. Uncommon before the age of 50 years, it is more common in women and particularly in blacks, with a male: female ratio of $1: 6(\mathbf{B}) .{ }^{1} \mathrm{~L} 4$ -L5 is the most commonly affected level and rarely exceeds $30 \%$ of the vertebral width. Degenerative spondylolisthesis is usually asymptomatic but may be associated with symptomatic stenosis of the lumbar spinal canal. The canal stenosis is the most common cause of back surgery in adults over 65 years when associated with neurogenic claudication. However, spinal stenosis is usually asymptomatic. Therefore, clinical radiological correlation is essential for making decisions (A). ${ }^{2}$ Surgical treatment with spinal decompression and stabilization in spondylolisthesis is recommended when conservative treatment fails $(\mathbf{B}){ }^{3}$

\section{How long SHOULD CONSERVATIVE tREATMENT (NON-OPERATIVE) BE MAINTAINED?}

In general, favorable functional outcomes in patients unresponsive to non-operative treatment are reported in groups with diverse etiologies for degenerative lumbar stenosis as well as time of conservative treatment (C). ${ }^{4-6}$ The time tested in this particular group of patients included in the clinical trial was 12 weeks. Patients treated conservatively without success and who underwent surgical treatment had better progression from a functional point of view, after 4 years of follow-up $(\mathbf{B}){ }^{?}$ 


\section{Recommendation}

After 12 weeks of unsuccessful conservative treatment, surgery is a treatment option for these patients $(\mathbf{B})$.

\section{IS IT NECESSARY TO REFER THE PATIENT TO ARTHRODESIS WITH USE OF RIGID PEDICLE SCREWS (NON-DYNAMIC)?}

The trials below discussed the value of fusion as treatment for spinal stenosis associated on one or two levels with degenerative spondylolisthesis.

Herkowitz and Kurz ${ }^{8}$ studied the isolated non-instrumented arthrodesis and showed that fusion produced less radicular pain (in the lower limbs) and better clinical outcome according to the surgeon's assessment (B). ${ }^{8}$ Bridwell et al. ${ }^{9}$ compared instrumented and non-instrumented fusion techniques. Patients undergoing instrumented fusion had less progression of spondylolisthesis and improved walking ability (B). ${ }^{9}$ Obtaining solid fusion was associated with subjective improvement. Both studies have methodological limitations: the control group was small (B) ${ }^{8,9}$

Fishgrund et al. ${ }^{10,11}$ in a randomized trial done in 1997, studied the effect of instrumentation on outcomes of spondylolisthesis, either arthrodesed or not. The authors found that the instrumentation increased the fusion rate but did not improve clinical outcomes (B). ${ }^{10,11}$ These studies have provided conflicting evidence according to which instrumentation would produce significant clinical improvement.

\section{Recommendation}

Instrumentation is an option in the treatment of degenerative spondylolisthesis to increase the chance of obtaining solid fusion and improve clinical outcomes (B).

\section{IS THE USE OF BONE SUBSTITUTES SUCH AS BMP (BONE MORPHOGENETIC PROTEIN) SAFE AND EFFECTIVE IN LUMBOSACRAL ARTHRODESIS?}

Regarding the rate of fusion, two studies ${ }^{12-14} \mathrm{~A}$ compared the use of osteoinductors (BMP) with iliac graft in patients with degenerative spondylolisthesis (single level), treated by means of neural decompression and non-instrumented intertransverse arthrodesis, with similar clinical and radiographic results $(\mathbf{B})$. However, there are many publications and case reports on complications arising from the use of BMP, including bone resorption and osteolysis, cage/graft migration, heterotopic ossification, radiculitis, formation of specific antibodies and bruises. ${ }^{15}$ Prospective and randomized studies are needed to elucidate the best clinical indications and safe dosages for the use of osteoinductors (BMP) in lumbosacral spine.

\section{Recommendation}

Due to the small number of studies on osteoinductors (BMP) and the high number of complications arising from their use, it was not possible to recommend its routine use for the treatment of these patients.

\section{WHAT IS THE MOST APPROPRIATE DIAGNOSTIC STUDY IN THIS CLINICAL CONTEXT?}

Plain radiographs in the standing position determine the diagnosis and the percentage of slippage in degenerative spondylolisthesis. Being available in most hospitals and since it is not an invasive test, this is the first additional test requested $(\mathbf{C}) .{ }^{16,17}$ Plain radiographs of the spine are effective to evaluate the bone structure of the spine and should be performed in the standing position to be more accurate in identifying the intervertebral disc height, lumbar lordosis and the degree of slippage between the vertebrae. Plain radiographs in anteroposterior incidence also allow assessment of the morphology of the articular facets. The lateral view also allows dynamic evaluation of the stability of the spine with studies of lumbosacral spine in maximum flexion and extension $(\mathbf{C}){ }^{22}$

Computed tomography is more sensitive and specific in identifying the narrowing of the spinal canal than plain radiography, because it allows visualization of the spinal canal in axial view. Myelography or CT myelography is more specific than non-specific CT scans and is important for the identification of spinal stenosis in patients with degenerative spondylolisthesis and neurologic symptoms. However, this is a test rarely used because it is invasive and is associated with adverse effects - secondary to ionizing radiation and contrast injection $(\mathbf{C}) .{ }^{18,19}$

In the presence of symptomatic lumbar stenosis, the most sensitive and specific radiologic examination is MRI, as it enables the visualization of soft tissues in the spine. MRI is the most accurate study to analyze the pathological anatomy of the narrowing of the spinal canal - produced by prolapsed intervertebral disc, hypertrophy of the ligamentum flavum, zygapophyseal joint hypertrophy, and vertebral slippage with intact vertebral arch $(\mathbf{C}) .{ }^{20}$ Dynamic myelography and CT myelography may be indicated to elucidate cases where there is a lack of association between symptoms and MR imaging for dynamic analysis or the presence of bony component contributing to the narrowing of the spinal canal. Another possibility for such an indication is MRI contraindicated in patients with pacemakers and claustrophobia. Sedation and open MRI are options for performing the test in patients with claustrophobia $(\mathbf{C}) \cdot{ }^{17-21}$ 


\section{Recommendation}

The most appropriate diagnostic test in this situation is plain radiography, which is more widely available; however, MRI is indicated for patients with symptomatic lumbar stenosis.

\section{BONE SUBSTITUTES ARE EQUAL OR SUPERIOR TO AUTOGRAFTS IN THIS SITUATION?}

Two randomized trials ${ }^{23,24}$ evaluated the association of bone expander beta-tricalcium phosphate to "local" bone tissue from the posterior vertebral elements, and compared their achieved results with autologous iliac graft, considered the gold standard in this clinical scenario. Both studies reported there were no clinical or radiographic differences between the groups assessed, and the use of bone expanders avoided the occurrence of pain in the iliac donor site $(\mathbf{A}) .^{23,24}$

\section{Recommendation}

The association of local bone graft (from the posterior vertebral elements) and beta-tricalcium phosphate is a therapeutic option for the removal of autologous bone graft from the iliac bone $(\mathbf{A})$.

\section{SHOULD THE SPONDYLOLISTHESIS BE REDUCED?}

In the search for Keywordsand indexed terms, 388 articles were retrieved; of these, 47 abstracts, and 3 comparative clinical trials chosen for analysis. A thorough analysis showed that the three articles were case series with small samples, and two showed a $60 \%$ loss on follow-up and conflicting results $(\mathbf{C}) \cdot{ }^{25-27}$ Due to the low quality of the articles, it was not possible to make a recommendation.

\section{Are there any Differences among the VARIOUS TYPES OF ARTHRODESIS?}

There are no randomized trials comparing the various methods of arthrodesis focusing on degenerative spondylolisthesis, especially with regard to intersomatic spacers. We found that lower-quality observational studies using different techniques for lumbar fusion and heterogeneous study populations showed a higher fusion rate in patients undergoing circumferential arthrodesis, but without evidence of better functional results $(\mathbf{B}){ }^{28-30}$

\section{Recommendation}

There are no randomized trials comparing the various methods of arthrodesis and use of intersomatic spacers in cases of degenerative spondylolisthesis; thus, it is not possible to recommend a specific technique $(\mathbf{B})$.

\section{References}

1. Jacobsen S, Sonne-Holm S, Rovsing H, Monrad H, Gebuhr P. Degenerative lumbar spondylolisthesis: an epidemiological perspective: the Copenhagen Osteoarthritis Study. Spine 2007;32:120-125.

2. Boden SD, Davis DO, Dina TS, Patronas NJ, Wiesel S. Abnormal magneticresonance scans of the lumbar spine in asymptomatic subjects: a prospective investigation. J Bone Joint SurgAm 1990;72:403-408.

3. Weinstein JN, Lurie JD, Tosteson TD, Hanscom B, Tosteson ANA, Blood EA, et al. Surgical versus Nonsurgical Treatment for Lumbar Degenerative Spondylolisthesis.NEngl J Med 2007; 356:2257-2270.

4. Atlas SJ, Keller RB, Wu Ya, et al. Long-term outcomes of surgical and nonsurgical management of lumbar spinal stenosis: 8 to 10 year results from the Maine lumbar spine study. Spine 2005;30:936.

5. Johnsson K, Udén A, Rosén I. The effect of decompression on the natural course of spinal stenosis: a comparison of surgically treated and untreated patients. Spine 1991;16:615.

6. Simotas AC, Dorey FJ, Hansraj KK, et al. Nonoperative treatment for lumbar stenosis: clinical and outcome results and a 3-year survivorship analysis. Spine 2000;15:197.

7. Weinsteinetal JN. Surgical Compared with Nonoperative Treatment for Lumbar Degenerative SpondylolisthesisJ Bone Joint Surg Am. 2009;91:1295304.

8. Herkowitz HN, Kurz LT. Degenerative lumbar spondylolisthesis with spinal stenosis. A prospective study comparing decompression with decompression and intertransverse process arthrodesis. J Bone Joint Surg Am. 1991 Jul;73(6):802-8

9. Bridwell KH, Sedgewick TA, O’Brien MF, Lenke LG, Baldus C.The role of fusion and instrumentation in the treatment of degenerative spondylolisthesis with spinal stenosis. J Spinal Disord 1993;6:461-72.

10. Fischgrund J, McKay M, Herkowitz H, Brower R, Montgomery D, Kurz L. Degenerative lumbar spondylolisthesis with spinal stenosis: A prospective, randomized study, comparing decompression and fusion with and without posterior pedicular instrumentation. Orth Trans 1997;21:158.

11. Fischgrund JS, Mackay M, Herkowitz HN, Brower R, Montgomery DM, Kurz LT. Degenerative lumbar spondylolisthesis with spinal stenosis: A prospective, randomized study comparing decompressive laminectomy and arthrodesis with and without spinal instrumentation. Spine1997;22:2807-12.

12. Hwang CJ, Vaccaro AR, Hong J, Lawrence JP, Fischgrund JS, Alaoui-Ismaili $\mathrm{MH}$, et al. Immunogenicity of osteogenic protein 1: results from a prospective, randomized, controlled, multicenter pivotal study of uninstrumented lumbar posterolateral fusion. J Neurosurg Spine. 2010;13(4):484-93.

13. Vaccaro AR, Anderson G, Patel T, Fischground J, Truumees E, Herkowitz $\mathrm{HN}$, et al. Comparison of OP-1 Putty (rhBMP-7) to iliac crest autograft for posterolateral lumbar arthrodesis: a minimum 2-year follow-up pilot study. Spine.2005;(24):2709-16.

14. Kanayama M, Hashimoto T, Shigenobu K, Yamane S, Bauer TW, Togawa D. A prospective randomized study of postero lateral lumbar fusion using osteogenic protein-1 (OP-1) versus local autograft with ceramic bone substitute: emphasis of surgical exploration and histologic assessment. Spine. 2006;31(10):1067-74

15. Mroz TE, Wang JC, Hashimoto R, Norvell DC. Complications related to osteobiologics use in spine surgery: a systematic review. Spine. 2010;35(9S):86104.

16. Fischgrund JS, Mackay M, Herkowitz HN, Brower R, Montgomery DM, Kurz LT. 1997 Volvo Award winner in clinical studies. Degenerative lumbar spondylolisthesiswith spinal stenosis: a prospective, randomized study comparing decompressive laminectomy and arthrodesis with and without spinal instrumentation. Spine. 1997;22(24):2807-2812.

17. Kanayama M, Hashimoto T, Shigenobu K, Oha F, Ishida T, Yamane S. Intraoperative biomechanical assessment of lumbar spinal instability: validation of radiographic parameters indicating anterior column support in lumbar spinal fusion. Spine. 15 2003;28(20):2368-2372.

18. Rosenberg NJ. Degenerative spondylolisthesis. Predisposing factors. J Bone Joint Surg Am. 1975;57(4):467-474.

19. Postacchini F, Perugia D. Degenerative lumbar spondylolisthesis.Part I: Etiology, pathogenesis, pathomorphology, and clinical features. Ital J OrthopTraumatol.1991;17(2):165-173.

20. Guglielmi G, De Serio A, Leone A, Agrosì L, Cammisa M. Imaging in degenerative disease of the lumbar spine. Rays. 2000 Jan-Mar;25(1):19-33. 
21. Corinthian Diagnostic Radiology, New York, NY, USA. Lumbar spinal stenosis assessment with computed tomography, magnetic resonance imaging, and myelography.ClinOrthopRelat Res. 2001 Mar;(384):12236.

22. Ohomori K. Clinical application of a novel assessment for lumbosacral stability J Neurosurg 2009 JUn 10("6) 587-594.

23. Gunzburg R, Szpalski M. Use of a novel beta-tricalciumphosphatebasedbonevoidfiller as a graftextender in spinal fusion surgeries. Orthopedics. 2002;25(5):591.

24. Dai LY, Jiang LS. Single-level instrumented posterolateral fusion of lumbar spine with beta-tricalcium phosphate versus autograft: a prospective, randomized study with 3-year follow up. Spine. 2008;33:1299-304.

25. Setti SR,Raju B. Reduction of spondylolisthesis Neurosurg Focus 13 (1):2, 2002
26. Haka J, Wroñski J. The role of reduction in operative treatment of spondylolytic spondylolisthesis Neurologia i Neurochirurgia Polska 2008; 42, 4: 345-352.

27. Matthiass HH, Heine J. The surgical reduction of spondylolisthesis. Clin Orthop 1986; 203: 34-44

28. Umeta RS, Avanzi O. Techniques of lumbar-sacral spine fusion in spondylosis: systematic literature review and meta-analysis of randomized clinical trials. Spine J. 2011 Jul;11(7):668-76. Epub 2011 Jun 8.

29. Han X, Zhu Y, Cui C, Wu YA. Meta-analysis of circumferential fusion versus instrumented posterolateral fusion in the lumbar spine. Spine. 2009 Aug 1;34(17):E618-25.

30. Zhou ZJ, Zhao FD, Fang XQ, Zhao X, Fan SW. Meta-analysis of instrumented posterior interbody fusion versus instrumented posterolateral fusion in the lumbar spine. J Neurosurg Spine. 2011 Sep;15(3):295-310. Epub 2011 May 27. 